\title{
Epidural Catheter Breakage During Insertion; A Cause Of Failed Epidural?
}

\section{Serchan P., Panteleou K., Tzima M., Zaimi D., Katsanoulas K., Katsika E. Hippokrateion General Hospital, Anaesthesiology Dept., Thessaloniki, Greece}

\section{BACKGROUND:}

$>$ Epidural catheter placement is a commonly performed procedure for providing anaesthesia or analgesia.

$>$ Epidural catheter breakage is a rare but worrisome complication.

$>$ Breakage is more often encountered during catheter removal than during its insertion.

$>$ Recommendations for the prevention of the complication do exist.

$>$ Interestingly, recommendations regarding whether or not a new epidural catheter should be placed are lacking.

\section{CASE REPORT:}

- Epidural catheter placement was required for labor analgesia in a 30 -year-old primigravid parturient, $1.73 \mathrm{~cm}$ height and $86 \mathrm{~kg}$ weight.

- Loss of resistance with air technique was used at the L3-L4 intravertebral space in the sitting position.

- The epidural space was identified at $4 \mathrm{~cm}$ from the skin with a 18-gauge Tuohy needle.

- The catheter was advanced up to $9 \mathrm{~cm}$; at this point resistance was encountered. Catheter removal through the needle was performed, when a tear of about $3 \mathrm{~mm} \times 0.4 \mathrm{~mm}$ at the catheter's radio-opaque tip was noticed. The Tuohy needle was removed and the procedure stopped.

$\checkmark$ Surgeon and patient were informed.

- Neurological examination was normal. After labour, X-rays of lumbar spine in antero-posterior and lateral position were unable to detect the retained catheter fragment. The neurosurgeon suggested a $\mathrm{CT}$ and MRI scan, but the fragment was again not visualized.

- The patient remained asymptomatic and was informed to report any adverse symptoms in the future.
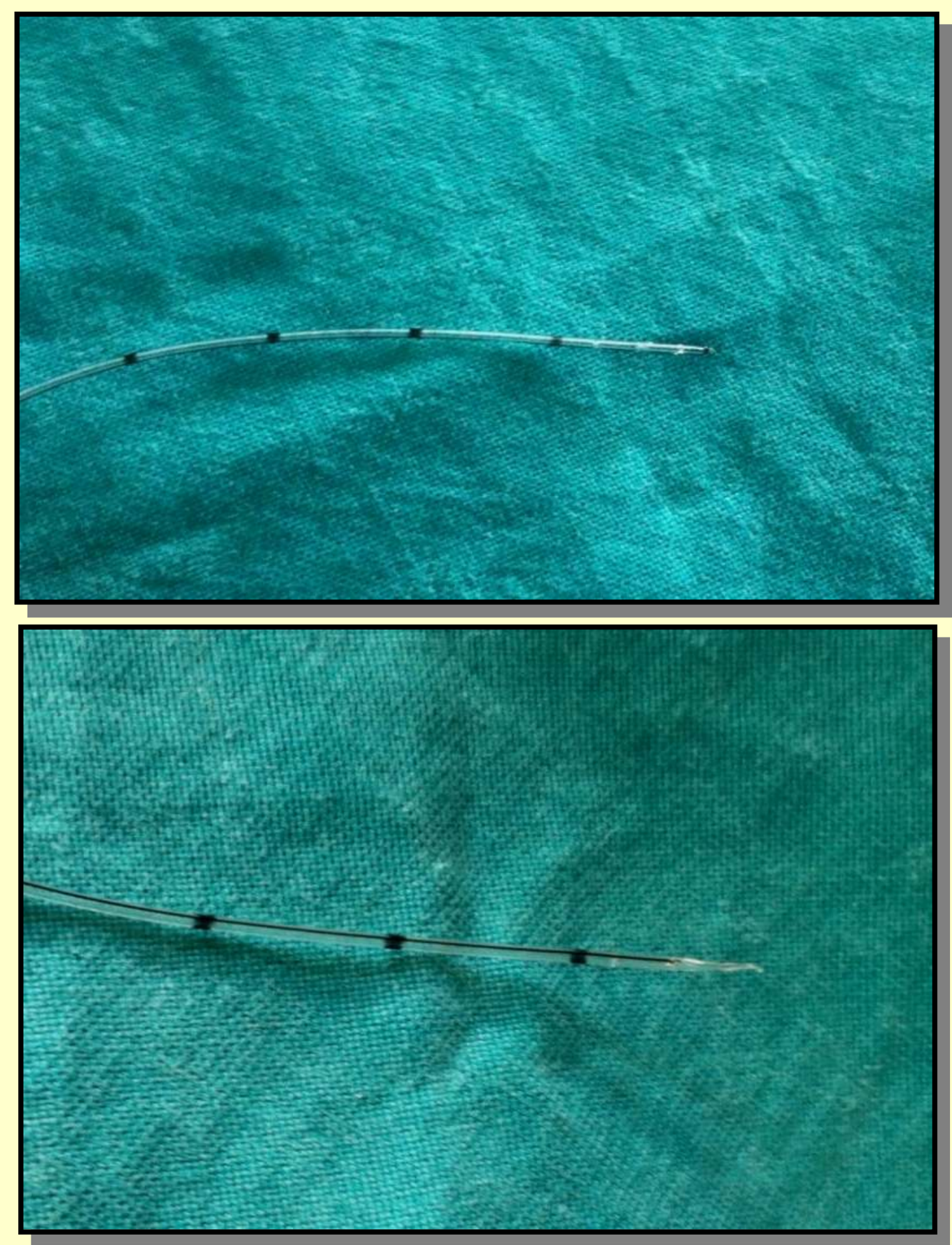

\section{DISCUSSION:}

- In order to prevent catheter breakage the epidural set must be inspected before placement for manufacturing defects.

During placement:

- When resistance is encoutered, excessive force should be avoided.

- The catheter should be withdrawn along with the needle.

- The maximum length in the epidural space should be $5 \mathrm{~cm}$.

When the catheter breaks:

- Imaging of any kind is not helpful in locating the catheter.

- It is safe to leave the fragments in place as long as there are no neurological symptoms.

- Literature review suggests that new epidural catheter placement at another intravertebral space has been uneventfully performed in awake, asymptomatic patients.

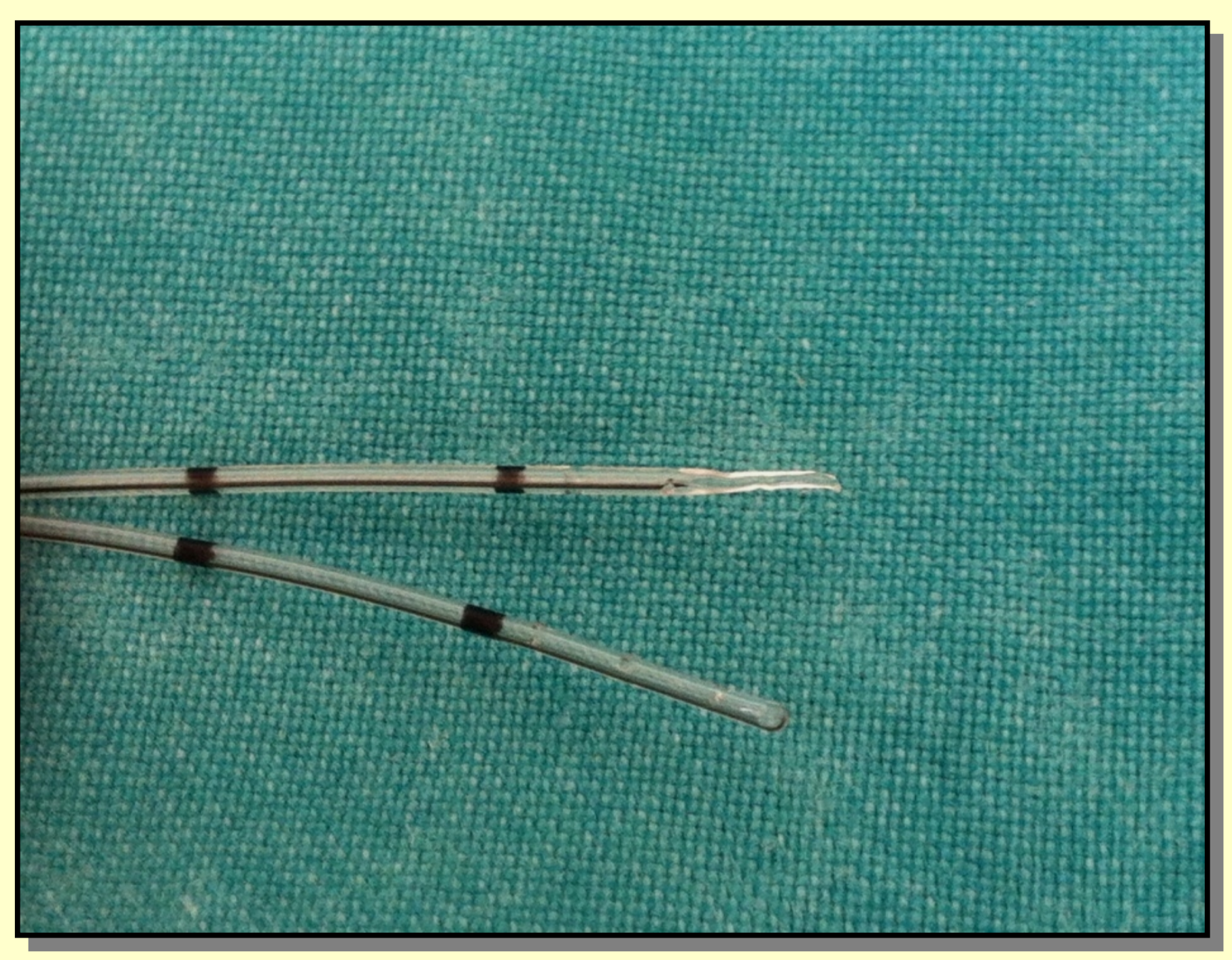

\section{LEARNING POINT:}

- Meticulous epidural access technique is necessary for successful catheter placement.

- In case of accidental breakage the patient should be informed.

- If asymptomatic it is safe to leave the fragment in place.

- A new catheter can be reinserted at another intervertebral space in asymptomatic patients after patients' informed consent.

- Surveillance for neurological symptoms is advised.

\section{REFERENCES:}

Üşar P, Kar AA, Çıtak G, Maral J, Canlı Ş. Breakage of an epidural catheter inserted for labor analgesia. Turk J Anaesthesiol Reanim. 2015 Aug;43(4):282-4.

Ritu S, Zia A, Ravi P, Karthik P,Brijbihari K. Broken epidural catheter; a rare complication. Journal of Case Reports in Practice (JCRP). 2014; 2(3): 72-73.

Deepanjali P, Pradeep J, Pravesh K, Jayashree S. Epidural Catheter Breakage:A Dilemma. Indian Journal of Anaesthesia. 2007; 51 (5) : 434437. 